\title{
Universiteit
}

Leiden

The Netherlands

\section{The impact of venous thrombosis on quality of life}

Korlaar, I.M. van; Vossen, C.Y.; Rosendaal, F.R.; Bovill, E.G.; Cushman, M.; Naud, S.; Kaptein, A.A.

\section{Citation}

Korlaar, I. M. van, Vossen, C. Y., Rosendaal, F. R., Bovill, E. G., Cushman, M., Naud, S., \& Kaptein, A. A. (2004). The impact of venous thrombosis on quality of life. Thrombosis Research, 114(1), 11-18. Retrieved from https://hdl.handle.net/1887/5086

Version: $\quad$ Not Applicable (or Unknown)

License:

Downloaded from: https://hdl.handle.net/1887/5086

Note: To cite this publication please use the final published version (if applicable). 


\title{
The impact of venous thrombosis on quality of life
}

\author{
Inez M. van Korlaar ${ }^{a, *}$, Carla Y. Vossen ${ }^{b}$, Frits R. Rosendaal ${ }^{b, c}$, \\ Edwin G. Bovill ${ }^{d}$, Mary Cushman ${ }^{\text {d,e }}$, Shelly Naud ${ }^{f}$, A.A. Kaptein ${ }^{a}$
}

\author{
a Unit of Psychology, Leiden University Medical Center, P.O. Box 9555, 2300 RB Leiden, The Netherlands \\ ${ }^{\mathrm{b}}$ Department of Clinical Epidemiology, Leiden University Medical Center, Leiden, The Netherlands \\ ${ }^{\mathrm{C}}$ Department of Hematology, Leiden University Medical Center, Leiden, The Netherlands \\ ${ }^{\mathrm{d}}$ Department of Pathology, University of Vermont, Burlington, VT, USA \\ ${ }^{e}$ Department of Medicine, University of Vermont, Burlington, VT, USA \\ ${ }^{\mathrm{f}}$ Department of Biostatistics, University of Vermont, Burlington, VT, USA
}

Received 10 March 2004; received in revised form 19 April 2004; accepted 20 April 2004

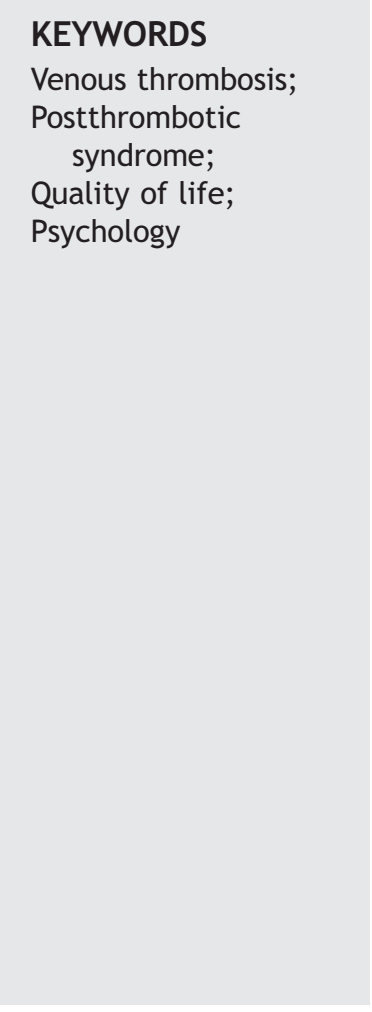

\begin{abstract}
Quality of life (QOL) is increasingly seen as an important outcome in clinical care. Etiology, diagnosis, and management of venous thrombosis have been studied extensively, but only few studies have examined the impact of venous thrombosis on quality of life.

The purpose of this study was to examine the impact of venous thrombosis on quality of life in a well-defined population of patients with venous thrombosis, by using both a generic and a disease-specific quality of life measure. A total of 45 patients from the thrombosis clinic of the University of Vermont in Burlington, VT, returned a mailed questionnaire including the Short-Form 36 (SF-36) and a diseasespecific venous thrombosis-quality of life (VT-QOL) questionnaire about the problems faced by patients with venous thrombosis.

The sample consisted of 13 men (28.9\%) and 32 women (71.1\%). The mean age was 44.1 years, with a range from 21 to 80 years. Compared with population norms of a general U.S. population that were adjusted for age and sex $(N=2463)$, venous thrombosis patients scored significantly lower $(p<0.05)$ on all subscales of the SF36. Patients with the postthrombotic syndrome (PTS) appeared to have more impairment in their quality of life as measured by both the SF-36 and the diseasespecific questionnaire. All correlations between the SF-36 subscales and the subscales of the VT-QOL were significant, most of them on a $p<0.01$ level. Given the impact of venous thrombosis and the postthrombotic syndrome on quality of life, assessment of QOL should be included in future studies on the outcome of venous thrombosis.

(C) 2004 Elsevier Ltd. All rights reserved.
\end{abstract}

* Corresponding author. Tel.: +31-71-527-5228; fax: +31-71-527-3668.

E-mail address: I.M.van_Korlaar@LUMC.nl (I.M. van Korlaar). 


\section{Introduction}

Whereas until about two decades ago, clinical and laboratory measurements were the only indicators of illness, recently, the patient's own view on his or her health has become increasingly important in clinical care and research. Researchers have developed a great number of self-report measurements to assess patients' own views on their functioning and quality of life (QOL) [1]. Several large clinical trials have shown that quality of life as an outcome measure is responsive to important clinical changes, and therefore it is increasingly seen as an important outcome measure in diagnostic and treatment studies [2]. The World Health Organization (WHO) definition of health is: 'A state of complete physical, mental and social well-being and not merely the absence of disease or infirmity' [3]. Based on this definition, quality of life in relation to health may be defined as 'the functional effect of an illness and its consequent therapy upon a patient, as perceived by the patient'. The domains that contribute to this effect are physical, psychological, and social functioning $[3,4]$.

The annual incidence of diagnosed venous thrombosis in western countries is 1 per 1000 persons [5,6]. In about $20 \%$ of patients, venous thrombosis extends proximally, and of those patients, 1-5\% develop fatal pulmonary embolism [7]. The postthrombotic syndrome (PTS) is a chronic condition consisting of leg pain, edema, venous ectasia, skin induration, and ulceration and is estimated to occur in up to $50 \%$ of patients after an episode of venous thrombosis $[8,9]$.

Etiology, diagnosis, and management of venous thrombosis have been studied extensively, but only a few studies have examined the impact of venous thrombosis on quality of life. Assessment of quality of life in conditions like venous thrombosis may provide important information on the burden of an illness that is not normally captured by traditional measures of morbidity [10].

A review on the subject of quality of life in patients with chronic venous diseases identified a total of 25 papers [11], of which 4 dealt with the assessment of QOL in venous thrombosis [12-15]. These studies indicate that patients with venous thrombosis report pain and impairment of their physical functioning. They also found that patients have low perceptions of their general health and high health distress. Impairment of QOL appears to be related to symptom severity and the presence of the postthrombotic syndrome.

Instruments used to measure quality of life can be classified into generic instruments and disease- specific instruments. Generic instruments allow comparison across populations of patients with different diseases, whereas disease-specific instruments are sensitive to key dimensions of quality of life that are impaired by specific diseases. An advantage of disease-specific instruments is that they increase acceptability of the questionnaire to the patient by including only relevant dimensions. A recommended research approach for assessing quality of life is the combination of generic and disease-specific instruments in order to combine the advantages of both methods [16-18]. Of the studies assessing $\mathrm{QOL}$ in patients with venous thrombosis mentioned above, only one study used both generic and disease-specific instruments to measure quality of life [13]. However, the authors failed to observe differences in the Short-Form 36 (SF-36) scores between patients with and patients without the postthrombotic syndrome.

The aim of this study was to examine the impact of venous thrombosis on quality of life in a welldefined population of patients with venous thrombosis by using both a generic and a newly developed disease-specific measure. The aim of the present study was to study the relationship between quality of life, the presence of symptoms, and the presence of the postthrombotic syndrome. An additional aim was to test the disease-specific questionnaire for a larger investigation.

\section{Materials and methods}

\section{Participants}

Patients seen by one of the authors (M.C.) at the thrombosis clinic of the University of Vermont were considered for participation. Their charts were reviewed for eligibility and the presence of postthrombotic syndrome. Individuals under the age of 18 years or who had comorbid disease were excluded from the study. A total of 86 eligible patients were selected to participate in the study. Of the selected patients, 3 refused, 2 were deceased, and 16 could not be reached. Following a telephone call by a research nurse, 65 patients (75.6\%) gave their consent to participate. The investigators contacted those 65 individuals by phone and sent out the questionnaire and consent forms by mail. Nonresponders received a reminder questionnaire. The research protocol was approved by the local institutional review board of the University of Vermont. 


\section{Measures}

\section{Demographic and illness-related variables}

The questionnaire included the following: age, sex, marital status, employment status, number of episodes of thrombosis, location of thromboses, time elapsed since last thrombosis, and a list of 11 symptoms that can be related to the postthrombotic syndrome. Patient charts were also reviewed to classify the presence of the postthrombotic syndrome as determined by a physician (M.C.).

\section{Quality of life}

As a generic quality of life instrument, the SF-36 was used [19]. The SF-36 is the most widely used and evaluated generic instrument to measure quality of life [20]. The SF-36 is a measure which assesses functional, psychological, and social status. It consists of 36 items spread over eight dimensions, plus a single item giving information on change in health over the past year. In addition to the eight subscales, two summary scores can be calculated: the Physical Component Summary (PCS) and the Mental Component Summary (MCS). A major advantage of the SF-36 is its extensive application in several disease conditions and excellent psychometric characteristics. The SF-36 has population norms available against which the results of this study will be compared [21].

As a disease-specific measure, a quality of life questionnaire developed by the authors was used (see Appendix A for sample items). The venous thrombosis-quality of life (VT-QOL) questionnaire was based on interviews held with thrombosis patients and previous QOL research in venous thrombosis $[14,22,23]$. The final instrument consisted of questions assessing quality of life in the dimensions physical functioning (7 items, $\alpha=0.96$ ), social functioning ( 6 items, $\alpha=0.94$ ), general mental health (6 items, $\alpha=0.94)$, and thrombosis repercussions (6 items, $\alpha=0.88$ ). We chose this approach because according to the existing literature about $\mathrm{QOL}$ measurement in patients with venous thrombosis, to accurately measure quality of life, it is imperative to focus on physical, emotional, and social functioning [24]. All items were rated on a five-point Likert scale. It is possible to calculate subscores on all subscales with a range of $0-100$ where 0 indicates worst possible quality of life and 100 indicates best possible quality of life. This is in line with the scoring of the SF-36. Additional questions were asked about the perceived severity of thrombosis, overall restriction in daily activities, and perceived pain.

\section{Statistical methods}

All data were entered and analyzed using SPSS 11.0. Means were calculated for all SF-36 subscales and compared to U.S. population norms adjusted for age and sex, by means of $t$-tests. Patients were grouped in three different ways: patients with and without PTS, patients with and without a recent event ( $<2$ years ago), and patients with one, two, or multiple events of venous thrombosis. To compare scores between groups, analysis of covariance (ANCOVA) was used and analyses were adjusted for age and sex. Simple univariate correlations were used to detect relationships between subscales of the SF-36 and the thrombosis-specific questionnaire. For all statistical tests, a $p$-value of 0.05 or less was considered significant.

\section{Results}

\section{Sample characteristics}

A total of 45 out of 65 patients $(69 \%)$ returned the questionnaire. The sample consisted of 13 men (28.9\%) and 32 women (71.1\%). The mean age was 44.1 years, with a range from 21 to 80 years. A total of 13 subjects were unemployed $(28.9 \%)$, of whom 6 were unemployed due to disability (13.3\%). Nonresponders were more likely to be male and were slightly younger than responders. No differences were seen between the two groups regarding the type of thrombosis the patients had experienced.

In the participant group, the number of patients with a recent thrombotic event, i.e., after 2000, was slightly lower than in the nonresponders. Respondents experienced between one and eight thrombotic events, with a median of two episodes. All 45 respondents experienced their most recent thrombotic event between 1997 and 2002, with a median elapsed time of 2 years; $38 \%$ had their most recent thrombotic event after 2000.

From chart review, it was concluded that 20 subjects $(44 \%)$ had no long-term physical effects from their venous thrombosis and 25 (56\%) had mild or severe postthrombotic syndrome. There were no significant differences in the presence of the postthrombotic syndrome with respect to age, sex, number of venous thromboses, and time elapsed since the last episode. Patients with PTS as diagnosed by a physician had a significantly higher number of self-reported symptoms compared to patients without PTS (3.4 vs. 1.4 , $p<0.01$ ). 


\section{Quality of life}

\section{Short-Form 36}

Because our sample was composed of a higher proportion of women and was older than the group used for the general U.S. population norms $(N=2463)$ [21], the U.S. population norms were adjusted by weighting the norms with the age and sex distribution in our sample. The venous thrombosis patients scored significantly lower on all subscales of the SF-36 (see Fig. 1). The scores on the Mental Health subscale are significantly lower at the $p<0.05$ level, and all others at the $p<0.01$ level.

Table 1 lists the means of the SF-36 subscales and summary scores for the three different groupings, namely, patients with a recent event and those with an event longer ago, patients with one, two, or multiple events, and patients with and without PTS. To determine significant differences between the groups, analyses of covariance were performed for the two summary scores. All analyses were adjusted for age and sex.

The presence of PTS was associated with lower SF-36 summary scores, indicating a worse quality of life for patients with PTS. However, only the difference in mean scores on the Physical Component Summary reached statistical significance [PCS: $F(1$, $39)=4.42, p<0.05$, MCS: $F(1,39)=1.35, p=0.25]$.

There is no significant relationship in quality of life scores between patients with a recent event and those without a recent event, when adjusted for PTS, although the Physical Component Summary is slightly lower for patients without a recent event and the Mental Component Summary is somewhat higher for this group [PCS: $F(4,38)=1.29, p=0.29$, MCS: $F(4,38)=1.14, p=0.35$ ].

The number of thrombotic events the patients had experienced was divided into three groups (one, two, or more than two events). A negative trend was observed between number of thrombotic events and Physical Component Summary. These mean scores were not found to be significantly different when adjusted for PTS $[F(5,37)=0.863$, $p=0.52]$.

Venous thrombosis-quality of life questionnaire Mean scores, standard deviations, and Cronbach's alpha's on the disease-specific questionnaire $(N=45)$ are shown in Table 2, along with correlations between the subscales of this diseasespecific measure and the subscales of the SF36. Cronbach's alpha's for all subscales are high (0.87-0.96), indicating a good internal consistency of the subscales. There were strong correlations of scores of the VT-QOL and SF-36 scores. In addition, pain and restriction in daily activities were significantly correlated with most subscales, especially physical functioning, physical role limitations, and bodily pain. Perceived severity did not correlate significantly with any of the SF-36 subscales.

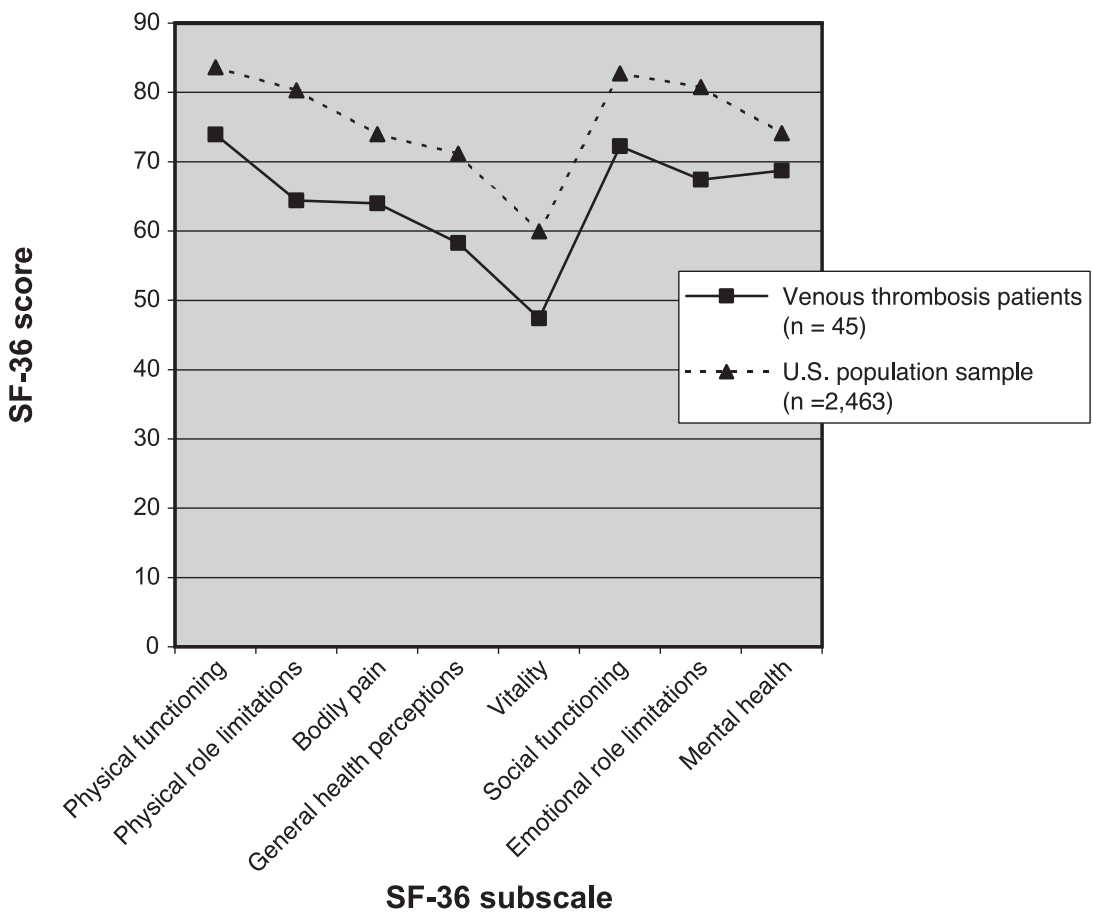

Fig. 1 Mean scores of venous thrombosis patients on the SF-36 compared to an U.S. population sample. 
Table 1 Mean SF-36 subscale and summary scores, for patients with and without a recent event, patients with and without the postthrombotic syndrome (PTS), and patients with one, two, or more events

\begin{tabular}{|c|c|c|c|c|c|c|c|c|c|}
\hline & \multirow{2}{*}{$\begin{array}{l}\text { U.S. } \\
\text { population } \\
\text { norms } \\
(N=2463)\end{array}$} & \multirow{2}{*}{$\begin{array}{l}\text { Venous } \\
\text { thrombosis } \\
\text { patients } \\
(N=45)\end{array}$} & \multicolumn{2}{|c|}{ Time since last event } & \multicolumn{2}{|c|}{ Presence of PTS } & \multicolumn{3}{|c|}{ Number of thrombotic events } \\
\hline & & & $\begin{array}{l}0-1 \text { year } \\
(N=17)\end{array}$ & $\begin{array}{l}>2 \text { years } \\
(N=28)\end{array}$ & $\begin{array}{l}\text { PTS } \\
(N=25)\end{array}$ & $\begin{array}{l}\text { No PTS } \\
(N=20)\end{array}$ & $\begin{array}{l}1 \\
(N=21)\end{array}$ & $\begin{array}{l}2 \\
(N=15)\end{array}$ & $\begin{array}{l}>3 \\
(N=9)\end{array}$ \\
\hline $\begin{array}{l}\text { Physical } \\
\text { functioning }\end{array}$ & 83.6 & 73.9 & 80.6 & 69.9 & 64.2 & 86.1 & 84.6 & 62.9 & 67.2 \\
\hline $\begin{array}{l}\text { Physical role } \\
\text { limitations }\end{array}$ & 80.3 & 64.4 & 58.8 & 67.9 & 58.0 & 72.5 & 78.6 & 55.0 & 47.2 \\
\hline Bodily pain & 74.0 & 64.0 & 61.6 & 65.4 & 56.0 & 74.0 & 75.2 & 54.7 & 53.1 \\
\hline $\begin{array}{l}\text { General health } \\
\text { perceptions }\end{array}$ & 71.2 & 58.3 & 59.6 & 57.5 & 55.0 & 62.4 & 60.9 & 58.2 & 52.1 \\
\hline Vitality & 59.9 & 47.4 & 44.4 & 49.3 & 43.5 & 52.0 & 52.1 & 40.4 & 47.2 \\
\hline $\begin{array}{l}\text { Social } \\
\text { functioning }\end{array}$ & 82.8 & 72.2 & 69.1 & 74.1 & 67.0 & 78.8 & 77.4 & 66.7 & 69.4 \\
\hline $\begin{array}{l}\text { Emotional role } \\
\text { limitations }\end{array}$ & 80.8 & 67.4 & 56.9 & 73.8 & 58.7 & 78.3 & 76.2 & 55.6 & 66.7 \\
\hline Mental health & 74.1 & 68.7 & 71.1 & 67.3 & 63.8 & 74.6 & 69.7 & 66.6 & 69.8 \\
\hline $\begin{array}{l}\text { Physical health } \\
\text { component }\end{array}$ & 50.0 & 44.2 & 45.2 & 43.6 & 41.0 & 48.1 & 49.1 & 40.1 & 39.1 \\
\hline $\begin{array}{c}\text { Mental health } \\
\text { component }\end{array}$ & 50.0 & 45.8 & 44.03 & 46.9 & 43.8 & 48.2 & 46.4 & 43.8 & 47.5 \\
\hline
\end{tabular}

To determine significant differences on the VT$\mathrm{QOL}$ between the groupings (patients with and without PTS, patients with and without a recent event, and patients with one, two, or multiple events), analyses of covariance were performed for all subscales. All analyses were adjusted for age and sex. Mean scores are listed in Table 3.

Patients with PTS have significantly lower scores on most VT-QOL than subjects without PTS, except for general mental health, perceived severity, and

Table 2 Mean scores, standard deviations and Cronbach's alpha on the venous thrombosis-quality of life (VT-QOL) questionnaire and correlations with SF-36 subscales for the venous thrombosis patient sample $(N=45)$

\begin{tabular}{|c|c|c|c|c|c|c|c|c|c|c|}
\hline \multirow{2}{*}{$\begin{array}{l}\text { Subscales } \\
\text { VT-QOL } \\
\text { (range) }\end{array}$} & \multirow{2}{*}{$\begin{array}{l}\text { Mean } \\
\text { (S.D.) }\end{array}$} & \multirow{2}{*}{$\begin{array}{l}\text { Cronbach's } \\
\text { alpha }\end{array}$} & \multicolumn{8}{|c|}{ SF-36 subscales } \\
\hline & & & $\mathrm{PF}$ & PR & $\mathrm{BP}$ & $\mathrm{GH}$ & VT & SF & ER & $\mathrm{MH}$ \\
\hline $\begin{array}{l}\text { Physical } \\
\text { functioning } \\
(0-100)\end{array}$ & $\begin{array}{l}76.4 \\
(28.5)\end{array}$ & 0.96 & $0.85^{* *}$ & $0.66^{* *}$ & $0.65^{* *}$ & $0.40^{* *}$ & $0.47^{* *}$ & $0.46^{* *}$ & $0.49^{* *}$ & $0.38^{*}$ \\
\hline $\begin{array}{l}\text { Social } \\
\text { functioning } \\
(0-100)\end{array}$ & $\begin{array}{l}83.6 \\
(22.5)\end{array}$ & 0.92 & $0.77^{* *}$ & $0.69^{* *}$ & $0.58^{* *}$ & $0.32^{*}$ & $0.45^{* *}$ & $0.50^{* *}$ & $0.61^{* *}$ & $0.50^{* *}$ \\
\hline $\begin{array}{l}\text { General mental } \\
\text { health } \\
(0-100)\end{array}$ & $\begin{array}{l}75.0 \\
(26.3)\end{array}$ & 0.94 & $0.70^{* *}$ & $0.65^{* *}$ & $0.66^{* *}$ & $0.68^{* *}$ & $0.87^{* *}$ & $0.78^{* *}$ & $0.76^{* *}$ & $0.84^{* *}$ \\
\hline $\begin{array}{l}\text { Thrombosis } \\
\text { repercussions } \\
(0-100)\end{array}$ & $\begin{array}{l}72.7 \\
(24.9)\end{array}$ & 0.87 & $0.51^{* *}$ & $0.51^{* *}$ & $0.51^{* *}$ & $0.44^{* *}$ & $0.52^{* *}$ & $0.54^{* *}$ & $0.49^{* *}$ & $0.61^{* *}$ \\
\hline Pain $(1-6)$ & $\begin{array}{l}2.1 \\
(1.3)\end{array}$ & & $-0.38^{*}$ & $-0.39^{*}$ & $-0.54^{* *}$ & -0.27 & -0.11 & -0.24 & -0.17 & -0.17 \\
\hline $\begin{array}{c}\text { Perceived } \\
\text { severity } \\
(1-5)\end{array}$ & $\begin{array}{l}3.5 \\
(1.3)\end{array}$ & & -0.05 & 0.12 & 0.24 & -0.03 & 0.06 & 0.03 & -0.07 & -0.12 \\
\hline $\begin{array}{l}\text { Restriction } \\
\quad(1-3)\end{array}$ & $\begin{array}{l}1.5 \\
(0.5)\end{array}$ & & $-0.62^{* *}$ & $-0.51^{* *}$ & $-0.46^{* *}$ & $-0.44^{*}$ & $-0.32^{*}$ & $-0.31^{*}$ & $-0.42^{* *}$ & -0.30 \\
\hline
\end{tabular}

PF: Physical functioning; PR: Physical role limitations; BP: Bodily pain; GH: General health perceptions; VT: Vitality; SF: Social functioning; ER: Emotional role limitations; $M H$ : Mental health. ${ }^{*} p<0.05$. ${ }^{* *} p<0.01$. 
Table 3 Mean scores on the VT-QOL, for patients with and without a recent event, patients with and without the postthrombotic syndrome (PTS), and patients with one, two, or more events

\begin{tabular}{|c|c|c|c|c|c|c|c|c|}
\hline & \multirow{2}{*}{$\begin{array}{l}\text { All patients } \\
(N=45)\end{array}$} & \multicolumn{2}{|c|}{ Time since last event } & \multicolumn{2}{|c|}{ Presence of PTS } & \multicolumn{3}{|c|}{ Number of thrombotic events } \\
\hline & & $\begin{array}{l}0-1 \text { year } \\
(N=17)\end{array}$ & $\begin{array}{l}>2 \text { years } \\
(N=28)\end{array}$ & $\begin{array}{l}\text { PTS } \\
(N=25)\end{array}$ & $\begin{array}{l}\text { No PTS } \\
(N=20)\end{array}$ & $\begin{array}{l}1 \\
(N=21)\end{array}$ & $\begin{array}{l}2 \\
(N=15)\end{array}$ & $\begin{array}{l}>3 \\
(N=9)\end{array}$ \\
\hline Physical functioning & 76.4 & 83.6 & 71.4 & 66.6 & 88.2 & 88.7 & 70.5 & 61.5 \\
\hline Social functioning & 72.7 & 87.3 & 81.3 & 76.6 & 92.5 & 89.9 & 77.8 & 80.1 \\
\hline General mental health & 83.6 & 75.2 & 74.8 & 67.2 & 84.4 & 81.3 & 69.2 & 70.8 \\
\hline $\begin{array}{l}\text { Thrombosis } \\
\text { repercussions }\end{array}$ & 75.0 & 75.0 & 71.3 & 63.7 & 83.5 & 83.8 & 66.7 & 58.3 \\
\hline Pain & 2.1 & 1.7 & 2.3 & 1.6 & 2.5 & 1.8 & 2.0 & 2.7 \\
\hline Perceived severity & 3.4 & 3.4 & 3.5 & 3.4 & 3.4 & 3.6 & 3.3 & 3.4 \\
\hline Restriction & 1.5 & 1.4 & 1.5 & 1.6 & 1.3 & 1.3 & 1.5 & 1.7 \\
\hline
\end{tabular}

restriction in daily activities [physical functioning: $F(3,39)=3.43, p<0.05$; thrombosis repercussions: $F(3,39)=3.42, p<0.05$; social functioning: $F(3$, 39) $=2.98, p<0.05$; pain: $F(3,39)=2.87, p<0.05$ ].

Patients with a recent event have significantly lower scores on the physical functioning and pain subscales of the VT-QOL, after adjusting for PTS [physical functioning: $F(4,36)=2.92, p<0.05$; pain: $F(4,36)=2.67, p<0.05]$. The other subscales did not reach statistical difference.

A significant negative trend in scores was observed between number of thrombotic events and scores on the physical limitations $[F(5,37)=2.83$, $p<0.05]$ and thrombosis repercussions subscales $[F(5,37)=2.86, p<0.05]$. This negative trend was less obvious in the other subscales. A positive trend in scores could be observed in pain and restriction in daily activities (meaning that patients with more thrombotic events experience more pain and are more restricted in their daily life), but these trends failed to reach statistical significance.

\section{Discussion}

The results of this study indicate that the quality of life of patients with venous thrombosis is impaired in all domains. This impairment encompasses physical, social, and psychological domains. Compared to a general U.S. population sample, venous thrombosis patients scored significantly lower on all subscales of the SF-36 after adjusting the population norms for the age and sex distribution in the sample.

The subjects in our study had their last thrombotic event a median of 2 years ago, which indicates that even after some years, quality of life of patients with venous thrombosis is still impaired. Given our results on both the SF-36 and thrombosisspecific instrument, we can also conclude that quality of life impairment is related to the pres- ence of self-reported symptoms and the presence of the postthrombotic syndrome as reported by a physician. Both findings are consistent with earlier research [12-15]. From our results on the VT-QOL, it can also be concluded that the quality of life of venous thrombosis patients is more impaired after multiple events.

A study by Kahn et al. [13] found that the postthrombotic syndrome had a significant impact on quality of life as measured by the diseasespecific measure VEINES-QOL, but no differences were observed in the SF-36 scores. In our study, however, we did detect significant differences $(p<0.05)$ in the Physical Health Component score between subjects with and subjects without the postthrombotic syndrome. On our venous thrombosis-quality of life questionnaire, those differences were even more obvious and were found across almost all dimensions. A reason for this could be that most patients in our study had experienced more than one thrombotic event, whereas in the study by Kahn et al., patients with recurrent venous thrombosis were excluded. Accordingly, the patients in our study might have had more severe manifestations of PTS.

The disease-specific QOL measure that we used in this study, the VT-QOL, was developed by our group and has not been formally evaluated for reliability and validity before, because the present study was the first study to use and validate this questionnaire. However, the good internal consistency and high correlations with the SF-36 subscales in this study give encouraging evidence for its reliability and validity and its future use. Its advantage to the SF-36 is the fact that it seems to be more sensitive to the specific problems venous thrombosis patients are facing, which can be concluded from its ability to detect differences between patients with and patients without PTS. Furthermore, unlike the SF-36, the instrument was able to discriminate between patients with 
one or multiple events and patients with or without a recent event.

When interpreting the results of this study, some limitations should be taken into consideration. We excluded patients with comorbid conditions such as cancer to avoid confounding by conditions that could affect quality of life in other ways. This could limit the generalizability of our study, but it is unlikely that it has affected the major conclusions. Nonresponders were more likely to have experienced a recent thrombotic event, which might have influenced the results, although time since last event was not found to be significantly associated with QOL. Presence of PTS is best determined for research purposes by a known scale such as the CEAP classification [25]. In our study, however, presence of PTS was determined by a single clinician at different points in time prior to the QOL assessment. The strong correlation between the classification of PTS by the clinician and the self-reported symptoms at the time of $\mathrm{QOL}$ determination suggests minimal impact of this possible confounding factor. Use of a single observer probably minimized the possibility of misclassification of PTS.

Given the observed impact of venous thrombosis and the postthrombotic syndrome on quality of life, assessment of QOL should be included in future studies on the outcomes of venous thrombosis, preferably with a disease-specific measure like the VT-QOL. Venous thrombosis is a multicausal disease that is caused by both genetic and environmental factors [26]. Future studies might also assess the impact of genetic testing for thrombophilia on quality of life. For clinical care, our results indicate that health-care givers should be sensitive about the impact of venous thrombosis on the well-being of their patients.

\section{Acknowledgements}

This research was supported by the NIH (grant PHS P01 HL-46703-P2Y11).

\section{Appendix A}

Sample items ${ }^{1}$ venous thrombosis-quality of life (VT-QOL) questionnaire.

During the past 4 weeks, to what extent did your thrombosis problem limit you while doing the following activities? (Please circle the number corresponding to the right answer.)

\begin{tabular}{|c|c|c|c|c|c|}
\hline & $\begin{array}{l}\text { Not limited } \\
\text { at all }\end{array}$ & $\begin{array}{l}\text { A little } \\
\text { limited }\end{array}$ & $\begin{array}{l}\text { Moderately } \\
\text { limited }\end{array}$ & $\begin{array}{l}\text { Very } \\
\text { limited }\end{array}$ & $\begin{array}{l}\text { Impossible } \\
\text { to do so }\end{array}$ \\
\hline \multicolumn{6}{|l|}{ Physical functioning } \\
\hline Finding a comfortable position to sleep & 1 & 2 & 3 & 4 & 5 \\
\hline Standing for a long time & 1 & 2 & 3 & 4 & 5 \\
\hline \multicolumn{6}{|l|}{ Social functioning } \\
\hline $\begin{array}{l}\text { Social or leisure activities in which you are standing for } \\
\text { long periods (e.g., parties, weddings, shopping, etc.) }\end{array}$ & 1 & 2 & 3 & 4 & 5 \\
\hline $\begin{array}{l}\text { Social or leisure activities in which you are sitting for } \\
\text { long periods (e.g., going to the cinema or theatre) }\end{array}$ & 1 & 2 & 3 & 4 & 5 \\
\hline \multicolumn{6}{|l|}{ General mental health } \\
\hline I feel on edge & 1 & 2 & 3 & 4 & 5 \\
\hline I feel I am a burden to others & 1 & 2 & 3 & 4 & 5 \\
\hline \multicolumn{6}{|l|}{ Thrombosis repercussions } \\
\hline I am frustrated about my thrombosis & 1 & 2 & 3 & 4 & 5 \\
\hline I am worried about my future because of my thrombosis & 1 & 2 & 3 & 4 & 5 \\
\hline
\end{tabular}

\section{References}

[1] Wood-Dauphinee S. Assessing quality of life in clinical research: from where have we come and where are we going? J Clin Epidemiol 1999;52:355-63.

[2] Wilson IB, Cleary PD. Linking clinical variables with health- related quality of life. A conceptual model of patient outcomes. JAMA 1995;273:59-65.

[3] Schipper H, Clinch J, Powell V. Definitions and conceptual

\footnotetext{
1 The complete questionnaire can be obtained from I.M. van Korlaar.
} 
issues. In: Spilker B, editor. Quality of life assessments in clinical trials : Raven Press, New York, 1990. pp. 11-24.

[4] Bowling A. Measuring disease: a review of disease specific quality of life measurement scales. Philadelphia (PA): Open Univ. Press, 2001.

[5] Anderson Jr FA, Wheeler HB, Goldberg RJ, Hosmer DW, Patwardhan NA, Jovanovic B, et al. A population-based perspective of the hospital incidence and case-fatality rates of deep vein thrombosis and pulmonary embolism. The Worcester DVT study. Arch Intern Med 1991;151: 933-8.

[6] Nordström M, Lindblad B, Bergqvist D, Kjellström T. A prospective study of the incidence of deep-vein thrombosis with a defined urban population. $J$ Intern Med 1992;232: 155-60.

[7] Turpie AG, Chin BS, Lip GY. Venous thromboembolism: pathophysiology, clinical features, and prevention. BMJ 2002; 325:887-90.

[8] Kahn SR, Solymoss S, Lamping DL, Abenhaim L. Long-term outcomes after deep vein thrombosis: postphlebitic syndrome and quality of life. J Gen Intern Med 2000;15:425-9.

[9] Prandoni P, Lensing AW, Cogo A, Cuppini S, Villalta S, Carta $M$, et al. The long-term clinical course of acute deep venous thrombosis. Ann Intern Med 1996;125:1-7.

[10] Lamping DL. Measuring health-related quality of life in venous disease: practical and scientific considerations. Angiology 1997;48:51-7.

[11] van Korlaar I, Vossen C, Rosendaal F, Cameron L, Bovill E, Kaptein A. Quality of life in venous disease. Thromb Haemost 2003;90:27-35.

[12] Beyth RJ, Cohen AM, Landefeld CS. Long-term outcomes of deep-vein thrombosis. Arch Intern Med 1995;155:1031-7.

[13] Kahn SR, Hirsch A, Shrier I. Effect of postthrombotic syndrome on health-related quality of life after deep venous thrombosis. Arch Intern Med 2002;162:1144-8.

[14] Mathias SD, Prebil LA, Putterman CG, Chieml JJ, Throm RC, Comerota AJ. A health-related Quality of Life Measure in patients with deep vein thrombosis: a validation study. Drug Inf J 1999;33:1173-87.

[15] Ziegler S, Schillinger M, Maca TH, Minar E. Post-thrombotic syndrome after primary event of deep venous thrombosis 10-20 years ago. Thromb Res 2001;101:23-33.

[16] Lamping DL. Chapter 7: Clinical outcomes and quality of life. Phlebology 1999;14(Suppl. 1):43-51.

[17] Fletcher A, Gore S, Jones D, Fitzpatrick R, Spiegelhalter D, Cox D. Quality of life measures in health care: II. Design, analysis, and interpretation. BMJ 1992;305:1145-8.

[18] Guyatt GH, Feeny DH, Patrick DL. Measuring health-related quality of life. Ann Intern Med 1993;118:622-9.

[19] Ware JE. SF-36 health survey: manual and interpretation guide. Boston: The Health Institute, New England Medical Center, 1993.

[20] Garratt A, Schmidt L, Mackintosh A, Fitzpatrick R. Quality of life measurement: bibliographic study of patient as sessed health outcome measures. BMJ 2002;324:1417-21.

[21] Ware JE, Kosinski M, Keller SD. SF-36 physical and mental health summary scales: a user's manual. Boston: Health Assessment Lab., New England Medical Center, 1994.

[22] Lamping DL, et al, VEINES Group. Measuring quality of life and symptoms in chronic venous disorders of the leg: development and psychometric evaluation of the VEINES-QOL/ VEINES-SYM questionnaire. Qual Life Res 1998;7:621-2.

[23] Launois R, Raboul-Marty J, Henry B. Construction and validation of a quality of life questionnaire in Chronic Lower Limb Venous Insufficiency (CIVIQ). Qual Life Res 1996;5: 539-54.

[24] Naughton MJ, Shumaker SA. The case for domains of function in quality of life assessment. Qual Life Res 2003; 12(Suppl. 1):73-80.

[25] Kistner RL, Eklof B, Masuda EM. Diagnosis of chronic venous disease of the lower extremities: the "CEAP" classification. Mayo Clin Proc 1996;71:338-45.

[26] Rosendaal FR. Venous thrombosis: a multicausal disease. Lancet 1999;353:1167-73. 